
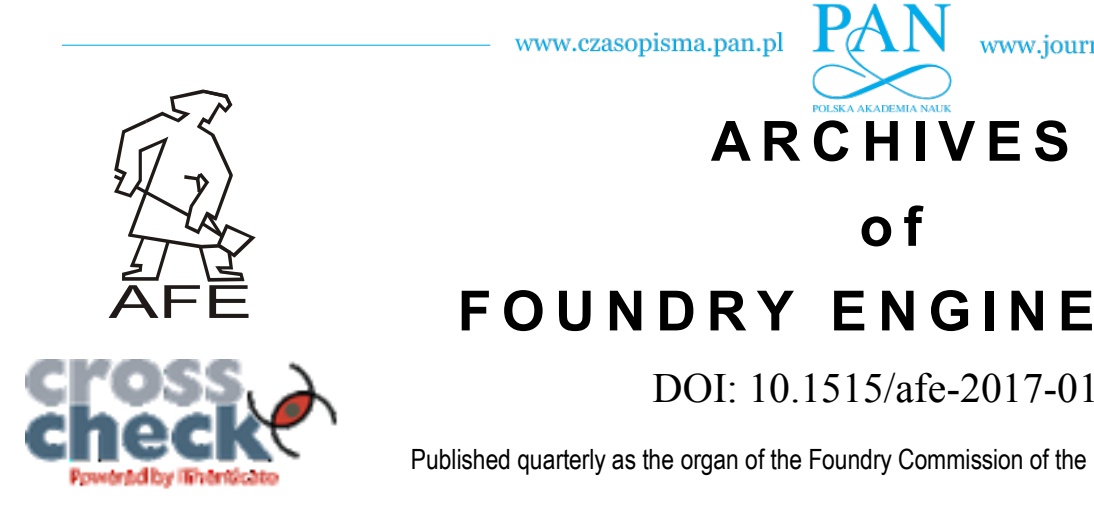

\title{
Microstructural and Mechanical Characterization of Solidified Austenitic Stainless Steels
}

\author{
G. Aktaş Çelik ${ }^{\text {a }}$, Ş. Polat ${ }^{\text {a, * }}$, Ş. H. Atapek ${ }^{\text {a }}$, G. N. Haidemenopoulos ${ }^{\text {b }}$ \\ ${ }^{a}$ Kocaeli University, Department of Metallurgical and Materials Engineering, \\ Umuttepe Campus 41380 Kocaeli, Turkey \\ ${ }^{\mathrm{b}}$ Thessaly University, Department of Mechanical Engineering, Laboratory of Materials, Volos, Greece \\ *Corresponding author. E-mail address: sydpolat@gmail.com
}

Received 25.04.2017; accepted in revised form 07.06.2017

\begin{abstract}
Among the family of stainless steels, cast austenitic stainless steels (CASSs) are preferably used due to their high mechanical properties and corrosion resistance. These steels owe their properties to their microstructural features consisting of an austenitic matrix and skeletal or lathy type $\delta$-ferrite depending on the cooling rate. In this study, the solidification behavior of CASSs (304L and 316L grades) was studied using ThermoCalc software in order to determine the solidification sequence and final microstructure during cooling. Theoretical findings were supported by the microstructural examinations. For the mechanical characterization, not only hardness measurements but also tribological studies were carried out under dry sliding conditions and worn surfaces were examined by microscopy and 3D profilometric analysis. Results were discussed according to the type and amount of microstructural features.
\end{abstract}

Keywords: Theory of crystallization, ThermoCalc, Metallography, Microstructure, Tribology

\section{Introduction}

Among the family of stainless steels, cast austenitic stainless steels (CASSs) are preferably used in in water reactors as joints, primary circuit pipes, elbows, internals and valves due to their high mechanical properties and corrosion resistance [1-6]. These steels owe their properties to their microstructural features consisting of an austenitic matrix and $\delta$-ferrite [3-4]. According to the literature, obtaining delta ferrite in solidified structure improves mechanical properties and corrosion resistance and minimizes the occurrence of hot cracks [1-4]. In most austenitic stainless steels, $\delta$-ferrite forms as primary phase during solidification according to Ferrite-Austenite (FA) solidification sequence specified by $\mathrm{Ni} / \mathrm{Cr}$ equivalent. On the other hand, $\delta$ ferrite morphology changes as skeletal, lathy and cellular type depending on the cooling rate. The ratio of $\gamma / \delta$ changes as well according to $\mathrm{Cr}$ and $\mathrm{Ni}$ equivalent [5].

In this study, (i) the solidification characteristics of the 304L and 316L cast austenitic stainless steels were investigated using computational thermodynamics and microstructural characterization, (ii) the mechanical properties of steels were investigated by means of both hardness measurements and wear tests under dry sliding conditions. 
Table 1.

The chemical composition of experimental steels (wt. \%).

\begin{tabular}{lllllll}
\hline Material & $\mathrm{C}$ & $\mathrm{Si}$ & $\mathrm{Mn}$ & $\mathrm{Ni}$ & $\mathrm{Cr}$ & $\mathrm{Mo}$ \\
\hline 304L & 0.06 & 0.29 & 0.87 & 8.90 & 18.10 & 0.35 \\
\hline 316L & 0.03 & 0.37 & 0.64 & 10.40 & 17.90 & 2.00 \\
\hline
\end{tabular}

\section{Experimental study}

\subsection{Material}

In the experimental study, 304L and 316L austenitic cast stainless steels, provided from a local casting company, were investigated. The chemical compositions of the steels are given in Table 1 .

\subsection{Computational method}

The solidification characteristics of $304 \mathrm{~L}$ and $316 \mathrm{~L}$ stainless steels were investigated by using thermodynamic calculations in ThermoCalc software according to CALPHAD (CALculations of PHase Diagrams) approaches. Equilibrium phase diagrams and the critical temperatures of the studied composition were computed using TCFE6 database. Solidification path and the microsegregation during solidification were calculated using the Scheil module. The simulation started from the liquid phase at casting temperature $\left(\mathrm{T}_{\mathrm{C}}\right)$ and ended at solidification temperature $\left(\mathrm{T}_{\mathrm{S}}\right)$. The most important assumption of the Scheil simulation is the absence of diffusion in the solid phases.

\subsection{Microscopic examinations}

In order to reveal the final microstructure of the studied 304L and $316 \mathrm{~L}$ stainless steels microscopic examinations were carried out. Cast samples were prepared metallographically by grinding with 320,600 , and 1000 mesh size $\mathrm{SiC}$ abrasives, respectively, and then polishing with $3 \mu \mathrm{m}$ diamond solution. Polished surfaces were etched electrochemically using $\% 10$ sodium metabisulphite under $5 \mathrm{~V}$ for $30 \mathrm{sec}$. The etched specimens were investigated using both Olympus BX41RF-LED model light microscope (LM) and Lieca QWin image analyzer for phase analysis. After the wear tests, worn surfaces of tested steels were characterized using LM and Nanovea PS50 model optical profilometer.

\subsection{Wear tests}

Wear tests were performed at room temperature using a "ballon-disc" type tribometer and $\mathrm{ZrO}_{2}$ balls were selected as counterpart material. In these tests, wear parameters like sliding speed, normal load and total sliding distance were adjusted as 0.1 $\mathrm{m} / \mathrm{s}, 10 \mathrm{~N}$ and $150 \mathrm{~m}$, respectively.

\section{Results and discussion}

\subsection{Modelling of the solidification sequence}

The solidification paths and the $\mathrm{C}$ isopleths of studied compositions are depicted in Figure 1 and 2, respectively. According to the solidification path of 304L steel (Fig. 1a), solidification starts with $\delta$-ferrite precipitation from liquid at liquidus temperature $\left(\mathrm{T}_{\mathrm{L}}\right)$, slightly over $1460{ }^{\circ} \mathrm{C}$, continues with austenite transformation at $1439^{\circ} \mathrm{C}$ and finishes at $1395{ }^{\circ} \mathrm{C}\left(\mathrm{T}_{\mathrm{S}}\right)$. However, solidification of $316 \mathrm{~L}$ steel, starts at $1456{ }^{\circ} \mathrm{C}$ with $\delta$ ferrite precipitation, austenite transforms starting from $1434{ }^{\circ} \mathrm{C}$ and solidification finishes at $1386{ }^{\circ} \mathrm{C}$ (Fig. 1b). The computed solidification sequence corresponds to the FA mode given in the literature [5]. The $\mathrm{C}$ isopleths of $304 \mathrm{~L}$ and $316 \mathrm{~L}$ steels show that, for both steels, the subsequent solid state transformations occur as $\mathrm{M}_{23} \mathrm{C}_{6}$ carbide precipitation and Laves phase forms during further cooling (Fig. 2).

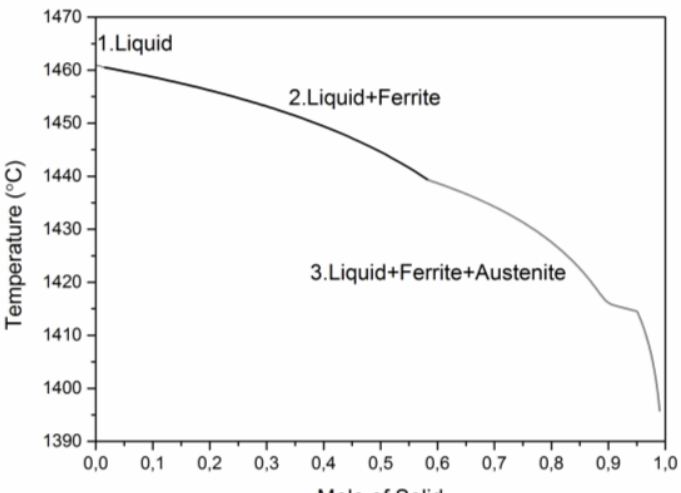

a)

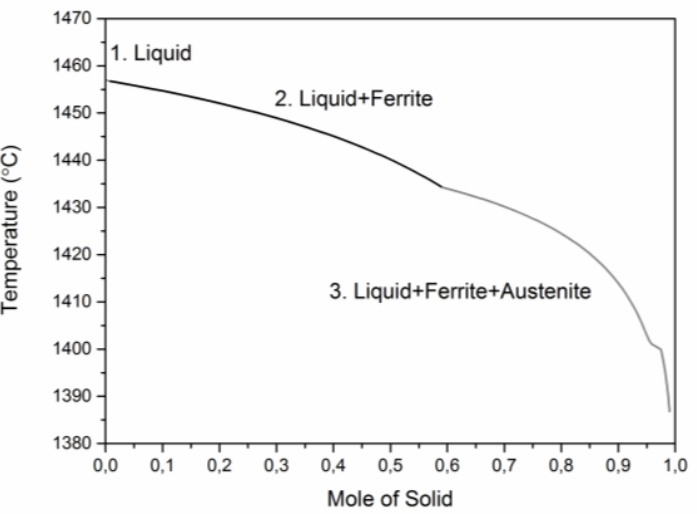

b)

Fig. 1. Solidification paths of the studied (a) $304 \mathrm{~L}$ and (b) $316 \mathrm{~L}$ stainless steels 


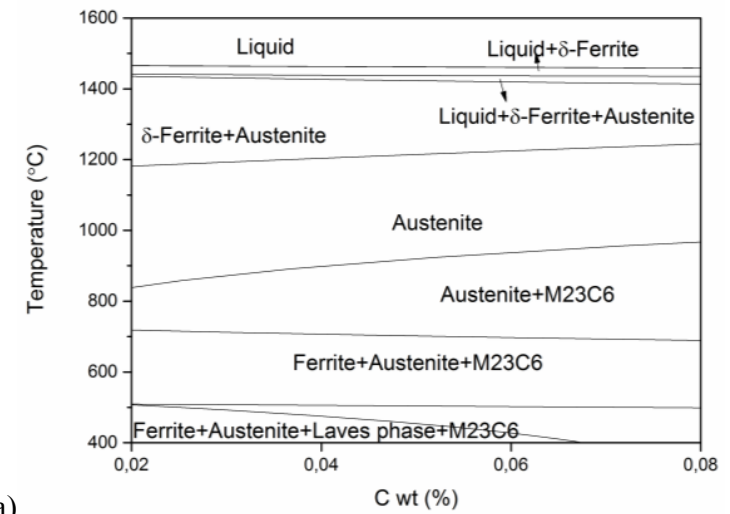

a)

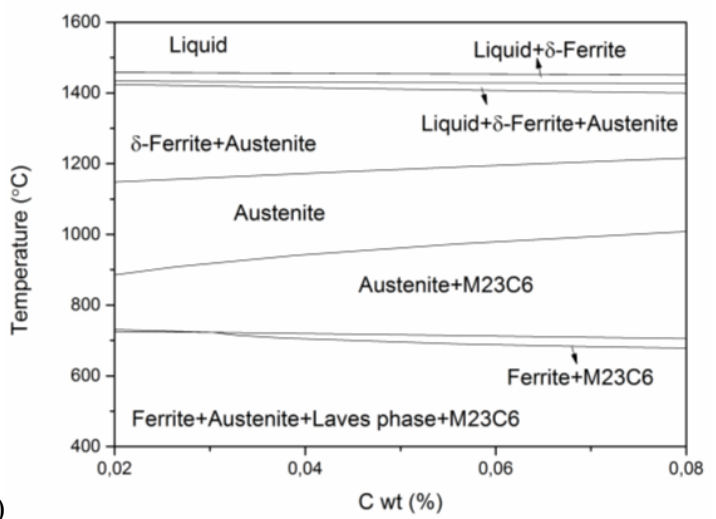

Fig. 2. Isopleth sections of the studied (a) 304L and (b) 316L stainless steels

\subsection{Microstructural characterization solidified structure}

The microstructures of cast $304 \mathrm{~L}$ and $316 \mathrm{~L}$ steels are given in Figure 3 . The solidified structures of the studied alloys have skeletal $\delta$-ferrite, austenite and cellular $\delta$-ferrite phases as shown in both Figure 3a and b. Image analyses indicate that 304L has $20 \%$ cellular $\delta$-ferrite and $4 \%$ skeletal $\delta$-ferrite in austenitic matrix while $316 \mathrm{~L}$ microstructure consists of $53 \%$ cellular $\delta$ ferrite, $2 \%$ skeletal $\delta$-ferrite and $45 \%$ austenite.

According to FA solidification mode, $\delta$-ferrite precipitates from the liquid. After $\delta$-ferrite nucleates from the melts, $\mathrm{Cr}$ is absorbed by the solid and $\mathrm{Ni}$ is rejected to the liquid, resulting in $\mathrm{Cr}$ depletion and $\mathrm{Ni}$ enrichment at the interface and austenite nucleates at the $\delta$-ferrite-liquid interface. Following the austenite formation, $\mathrm{Cr}$ becomes enriched and $\mathrm{Ni}$ becomes depleted at the austenite-liquid interface, which favors for the formation of $\delta$ ferrite. Thus, the alternating formation of $\delta$-ferrite and austenite at the interface occurs $[5,7]$. Due to higher Ni content, $316 \mathrm{~L}$ has higher austenite and lower $\delta$-ferrite fraction which leads to a higher hardness level than that of 304L. Although, according to isopleths given in Figure 2, formation of $\mathrm{M}_{23} \mathrm{C}_{6}$ and Laves phase during cooling are expected, these phases are not seen in the LM micrographs (Fig. 3).

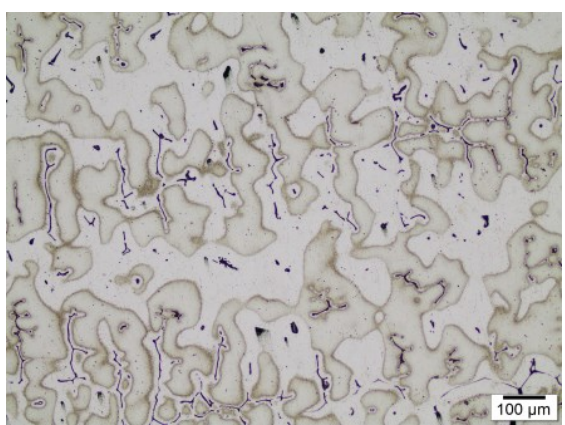

a)

b)

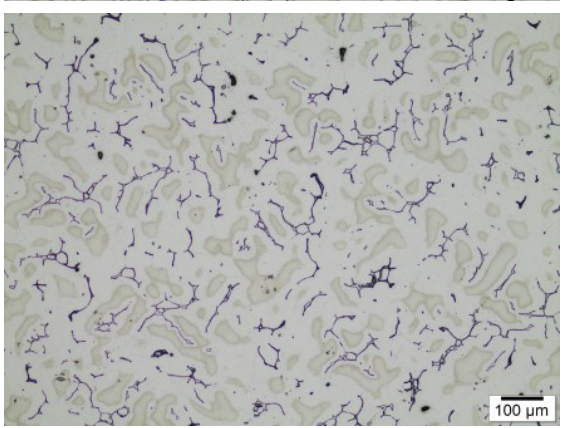

Fig. 3. LM micrographs showing the microstructures of cast (a) 304L and (b) 316L steels

\subsection{Evaluation of wear tests}

Tribological properties of studied steels were evaluated using the friction coefficient values and the volume loss data obtained by room temperature wear tests. Friction coefficient values are given in Figure 4. Under the given tribological conditions, friction coefficient values of 304L steel vary between $0.18-0.25$ while $316 \mathrm{~L}$ steel has friction coefficient values between $0.10-0.18$. This difference can be attributed to the higher surface hardness and $\delta$ ferrite ratio of 304L steel. As it is known, friction force is directly proportional to shear strength and contact area [8]. Figure 4 suggests that; (i) shear strength is the dominant factor for determining the value of friction coefficient since harder steel has higher friction coefficient [8], (ii) higher work hardening capability of 316L results in lower friction coefficient values [8]. According to worn surface investigations given in Section 3.4, it can be concluded that friction coefficient value of $316 \mathrm{~L}$ steel increases as sliding distance increases, due to the spallation of the adhesive layers (Fig. 4).

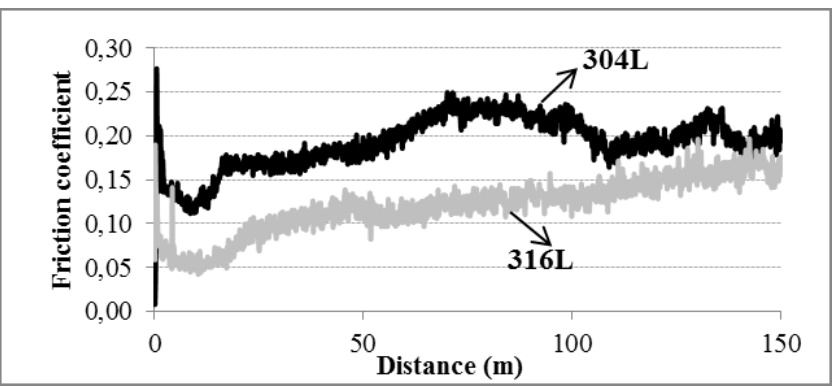

Fig. 4. Friction coefficient values as a function of distance obtained by "ball-on-disc" type tribometer at room temperature 
Volume loss values of studied steels were calculated from the volume loss data using wear tracks. Figure 5 shows the volume loss and hardness values. It is clearly seen that in 304L volume loss is lower than 316L making it more wear resistant under the studied dry sliding conditions. This should be expected since the $\delta$-ferrite and hardness are higher in 304L steel.

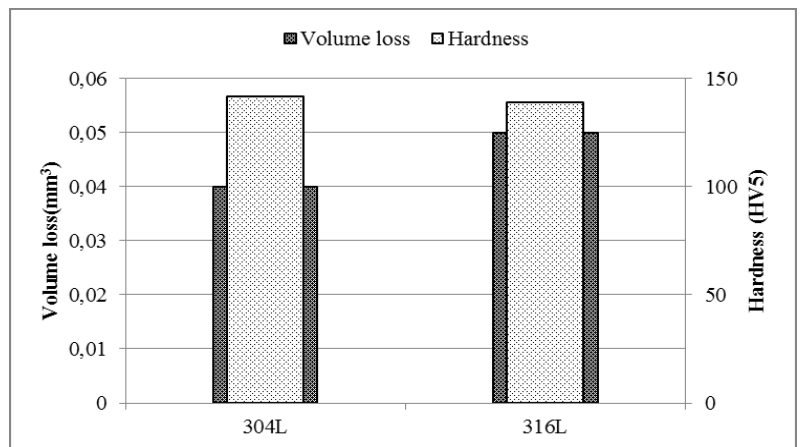

Fig. 5. Volume loss and hardness data for 304L and 316L steels

\subsection{Worn surfaces investigations}

Images obtained by optical profilometry showing the worn surfaces of specimens are given in Figure 6. Worn surface images show that although width of the wear track is similar for both steels, 316L has deeper track as a result of which higher specific wear rate occurs (Fig. 6).

a)

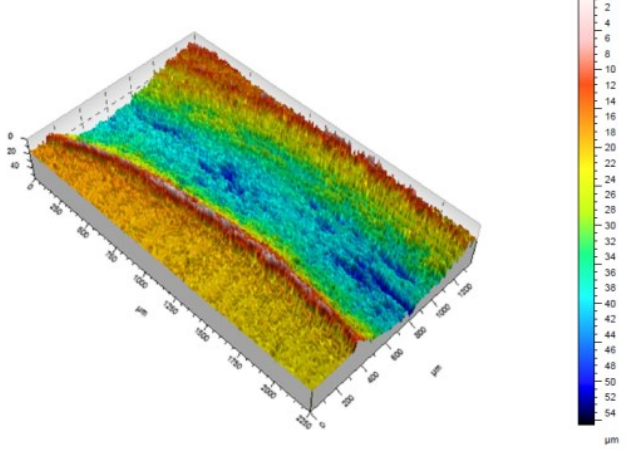

b)

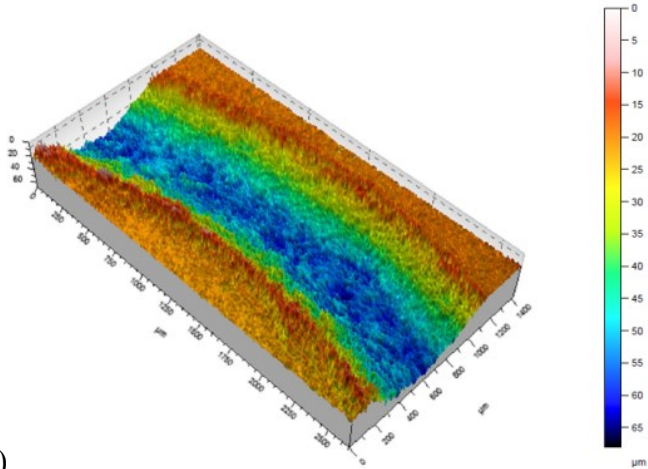

Fig. 6. Optical profilometer images showing the worn surfaces of (a) $304 \mathrm{~L}$ and (b) $316 \mathrm{~L}$
LM micrographs showing the worn surfaces of specimens are given in Figure 7. In both steels, abrasive and adhesive wear occurred. However, as hardness decreased from $304 \mathrm{~L}$ to $316 \mathrm{~L}$, dominant wear mechanism changed from abrasive to adhesive wear. The adhesive layer formed due to the higher plastic deformation ability of austenite phase [9]. Thus, in 316L where austenite phase has higher volume, adhesive layers increased and their spallation caused deeper wear track (Fig. 6b) and higher specific wear rate (Fig. 5).

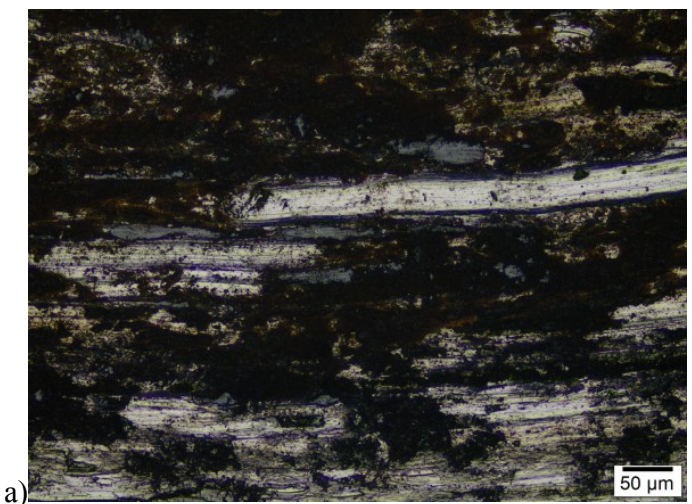

b)

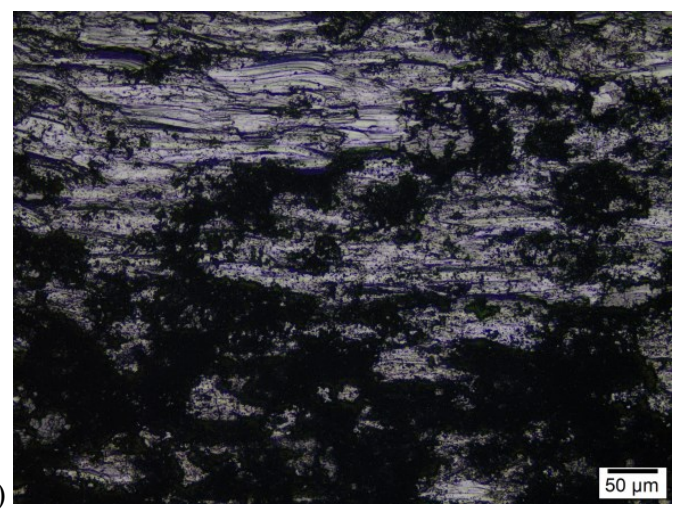

Fig. 7. LM micrographs showing the worn surfaces of (a) 304L and (b) $316 \mathrm{~L}$

\section{Conclusions}

In the present study, (i) the solidification characteristics of the $304 \mathrm{~L}$ and $316 \mathrm{~L}$ cast austenitic stainless steels were investigated using computational thermodynamics and microstructural characterization, (ii) the mechanical properties of steels were investigated by means of both hardness measurements and wear tests under dry sliding conditions. Results concluded that; (i) solidification started with $\delta$-ferrite precipitation from the liquid and finished after the austenite transformation, (ii) the final microstructures of both steels consisted of skeletal $\delta$-ferrite and cellular $\delta$-ferrite in austenitic matrix, (iii) $316 \mathrm{~L}$ steel had lower $\delta$ ferrite phase and lower hardness than 304L steel, (iv) 304L steel had higher friction coefficient value due to higher shear strength [8], (v) 304L steel had lower volume loss, (vi) dominant mechanism was adhesive wear in the studied steels. 


\section{References}

[1] Chen, W.Y., Li, M., Kirk, M.A., Baldo, P.M. \& Lian, T., (2016). Effect of heavy ion irradiation on microstructural evaluation in CF8 cast austenitic stainless steel. Journal of Nuclear Materials. 471, 184-192. DOI: 10.1016/ j.jnucmat.2015.08.032

[2] Cheon, J.S. \& Kim, I.S. (2000). Evaluation of thermal aging embrittlement in CF8 duplex stainless steel by small punch test. Journal of Nuclear Materials. 278, 96-103. PII: S 002 2 - 3115 (99)000213-5

[3] Li. M., Miller, M.K. \& Chen, W-Y. (2015). Phase stability in thermally-aged CASS CF8 under heavy ion irradiation. Journal of Nuclear Materials. 462, 214-220. DOI: 10.1016/ j.jnucmat.2015.03.034

[4] Jang, H., Hong, S., Jang, C. \& Lee, J.G. (2014). The effects of reversion heat treatment on the recovery of thermal aging embrittlement of CF8M cast stainless steels. Materials and Design. 56, 517-521. DOI: 10.1016/j.matdes.2013.12.010
[5] Fu, J.W., Yang, Y.S., Guo, J.J., Ma, J.C. \& Tong, W.H. (2009). Microstructure evolution in AISI 304 stainless steel during near rapid directional solidification. Materials Science and Technology. 25, 1013-1016. DOI: 10.1179/ 174328408 X317093

[6] Inoue, H. \& Koseki, T. (2017). Solidification mechanism of austenitic stainless steels solidified with primary ferrite. Acta Materialia. $124, \quad 430-436 . \quad$ DOI: $10.1016 /$ j.actamat.2016.11.030

[7] Hunter, A. \& Ferry, M. (2002). Phase formation during solidification of AISI 304 austenitic stainless steel. Scripta Materialia. 46, 253-258. PII: S13 5 9-6 462 (0 1 )0 121 5- 5

[8] Holmberg, K. \& Matthews, A. (2009). Coatings tribology, properties, mechanisms, techniques and applications in surface engineering. (2nd ed.). Oxford: Elsevier.

[9] Totten G.E. (2006). Steel heat treatment handbook. (2nd ed.). London: Taylor \& Francis Group. 